\title{
Aortocoronary graft flow and reactive hyperaemia in relation to postoperative myocardial infarction
}

\author{
S. SKOT N ICKI, J. VONK, TH. SLEEGERS, \\ S. DER CKSEN, G . L I N S EN, L. LACQUET, \\ and P. KUIJPERS \\ Departments of Thoracic and Cardiovascular Surgery, Cardiology, and Anaesthetics, \\ University of Nijmegen, Nijmegen, The Netherlands
}

\begin{abstract}
Skotnicki, S., Vonk, J., Sleegers, Th., Dercksen, S., Linssen, G., Lacquet, L.; and Kuijpers, P. (1976). Thorax, 31, 172-177. Aortocoronary graft flow and reactive hyperaemia in relation to postoperative myocardial infarction. Blood flow through aortocoronary venous grafts and its response to a brief period of arterial occlusion-reactive hyperaemia-were studied in relation to the development of postoperative myocardial infarction. In 40 patients with intractable angina due to obstructive coronary artery disease, 72 aortocoronary venous grafts were constructed. In $18 \%$ of the grafts there was no response to the flow to temporary occlusion, due to absence of reactive hyperaemia. In the remaining grafts the flow increased from $17 \%$ to $26 \%$. In $17.5 \%$ of the patients postoperative myocardial infarction was diagnosed. No relation could be established between this control flow through aortocoronary grafts and postoperative myocardial infarction. A significant difference was found in the magnitude of the reactive hyperaemia following occlusion of the graft between patients who developed myocardial infarction $(13.0 \%)$ and those who did not $(26.8 \%)$. Some of our observations suggest that the myocardium is in a state of reactive hyperaemia after coronary surgery. With certain technical precautions the flow changes caused by reactive hyperaemia can be used as an indicator of the result to be expected from bypass surgery.
\end{abstract}

Coronary artery surgery has been established in the treatment of ischaemic heart disease (Favoloro et al., 1970; Johnson and Lepley, 1970; Cooley et al., 1973; Grondin et al., 1974). Several factors can contribute to the objective assessment of the results:

1. initial blood flow measurements through the graft at the time of operation (Grondin et al., 1971)

2. the calibre of the graft and the turbulence at the distal anastomosis (Edwards, 1971)

3. the calibre of the recipient coronary arteries (Furuse et al., 1972)

4. the distal run-off (Grondin et al., 1972)

5 . the vasodilator capacity of the coronary circulation by means of reactive hyperaemia (Bittar et al., 1972; Reneman and Spencer, 1972).
The purpose of this study was to measure the flow through the aortocoronary grafts (control flow) and the response of this flow to temporary arterial occlusion (reactive hyperaemia). Further, the relation between reactive hyperaemia and the development of a myocardial infarction in the preand early post-operative period was investigated.

\section{PATIENTS AND METHODS}

A consecutive series of 40 patients operated on between January and November 1974 in our department are the subject of this study. The indication for surgery was intractable angina in patients with obstructive coronary artery disease. They were all men and their ages ranged from 34 to 60 years. All operations were performed with total cardiopulmonary bypass under moderate hypothermia with intermittent cross-clamping of 
the aorta and electrically induced fibrillation. The saphenous vein from the lower leg was used for aortocoronary bypass. Graft flow was measured with a Statham Model SP 2201 pulsed squarewave electromagnetic flowmeter, just after extracorporeal circulation was stopped, in a stable haemodynamic state with the heart beating spontaneously. In 27 patients reactive hyperaemia was measured after a 10 -second period of occlusion of the graft. Because the time of extracorporeal perfusion and the time of cross-clamping of the aorta during surgery could influence peripheral vascular resistance in the coronary circulation and reactive hyperaemia, these timeperiods were also noted.

Graft flow before and during reactive hyperaemia was analysed in relation to the development of a postoperative myocardial infarction in the early postoperative period (seven days). Myocardial infarction was diagnosed according to the usual electrocardiographic criteria (development of abnormal $\mathbf{Q}$ waves, loss of amplitude $\mathbf{R}$ waves, persistent $T$-wave abnormalities, and increased enzymatic activity of serum aspartate aminotransferase (SGOT) and lactic dehydrogenase (LDH), with a normal serum alanine aminotransferase (SGPT) value. As a significant increase of enzyme activity we accepted values higher than twice normal (normal values in our laboratory: SGOT $15 \mathrm{U} / 1$, LDH $140 \mathrm{U} / 1$, SGPT 7 U/1).

\section{RESULTS}

Forty patients received 72 grafts to the distal part of the coronary artery. There were 23 bypasses to the right coronary artery (RCA), 35 to the left anterior descending artery (LAD), and 14 to the circumflex artery (C). Sixty were separately anastomosed with the ascending aorta and 12 by means of a Y-connection (in pairs).

Table I and Fig. 1 show the values of control flow through the different bypasses and Table II presents the flow changes during the period of reactive hyperaemia after 10 seconds' occlusion

T A B L E I AORTOCORONARY BYPASS FLOW

\begin{tabular}{l|ccc}
\hline & $\begin{array}{c}\text { No. of Bypasses } \\
\text { investigated }\end{array}$ & $\begin{array}{c}\text { Range of Control } \\
\text { Bypass Flow } \\
\text { (ml/min) }\end{array}$ & $\begin{array}{c}\text { Mean Control } \\
\text { Bypass Flow } \\
\text { (ml/min) }\end{array}$ \\
\hline R C A & 21 & $0-280$ & 136 \\
LA D & 30 & $20-330$ & 145 \\
Circ. & 9 & $50-160$ & 92 \\
Y-grafts & $6 \times 2$ & $100-400$ & 185 \\
\hline
\end{tabular}

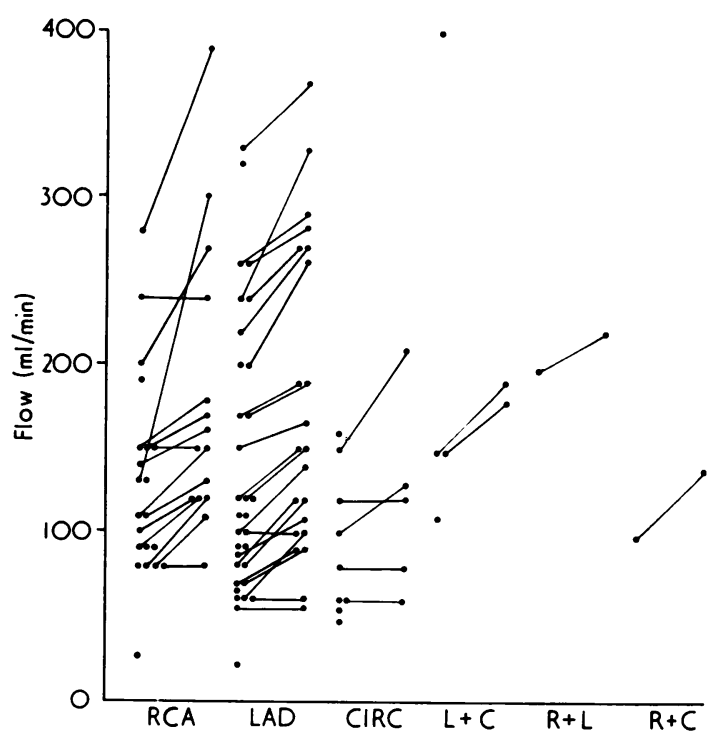

FIG. 1. Flow through the aortocoronary venous grafts to $R C A$ (right coronary artery), LAD (left anterior descending), CIRC (circumflex artery), and double grafts by means of $Y$-connection. The first points represent control flow, and the second ones change after 10 seconds' occlusion (reactive hyperaemia).

\section{T A B L E I I}

AORTOCORONARY BYPASS FLOW BEFORE AND AFTER 10 SECONDS' GRAFT OCCLUSION (REACTIVE HYPERAEMIA (RH))

\begin{tabular}{l|cccc}
\hline & $\begin{array}{c}\text { No. of } \\
\text { Bypasses } \\
\text { investigated }\end{array}$ & $\begin{array}{c}\text { Mean Control } \\
\text { Bypass Flow } \\
\text { (ml/min) }\end{array}$ & $\begin{array}{c}\text { Mean Bypass } \\
\text { Flow during } \\
\text { RH (ml/min) }\end{array}$ & $\begin{array}{c}\text { Increase of } \\
\text { Bypass } \\
\text { Flow \% }\end{array}$ \\
\hline R C A & 15 & $143(80-280)$ & $180(80-390)$ & 26 \\
L A D & 22 & $151(60-330)$ & $176(60-330)$ & 17 \\
Circ. & 5 & $102(60-150)$ & $120(60-210)$ & 18 \\
Y-grafts & $4 \times 2$ & $150(100-200)$ & $182(140-220)$ & 21 \\
\hline
\end{tabular}

of the graft. Control flow was measured in all patients, the flow during reactive hyperaemia in 27 patients.

RIGHT CORONARY ARTERY The mean control flow in 21 grafts was found to be $136 \mathrm{ml} / \mathrm{min}$; in 15 grafts flow measurements were made during reactive hyperaemia. After 10 seconds' occlusion the flow increased to a mean value of $180 \mathrm{ml} / \mathrm{min}$ in 12 bypasses, a change of $26 \%$. In three grafts there was no influence of reactive hyperaemia on the graft flow.

LEFT ANTERIOR DESCENDING ARTERY The mean control flow in 30 grafts was found to be $145 \mathrm{ml}$ / min. The response after 10 seconds' occlusion was 
observed in 22 grafts: in 19 the flow rose to a mean value of $176 \mathrm{ml} / \mathrm{min}$ (a change of $17 \%$ ); in three grafts no increase of flow was observed.

CIRCUMFLEX ARTERY The mean control flow in nine grafts was found to be $92 \mathrm{ml} / \mathrm{min}$. The response after 10 seconds' occlusion was observed in five grafts. In two the flow rose to a mean value of $120 \mathrm{ml} / \mathrm{min}$ (a change of $17 \%$ ) and in three grafts it remained unchanged. Figure 2 presents an example of control flow and the reactive hyperaemia following 10 seconds' occlusion of the graft to the circumflex artery.

Y-GRAFTS The mean control flow in six Y-grafts was considerably higher than in single grafts (mean $185 \mathrm{ml} / \mathrm{min}$ ). In all four grafts in which the reaction to reactive hyperaemia was measured, an increase of the flow, $140-220 \mathrm{ml} / \mathrm{min}$, was observed (a change of $21 \%$ ).

RELATION BETWEEN PERFUSION TIME AND REACTIVE HYPERAEMIA No significant relation between reactive hyperaemia and total perfusion time of extracorporeal circulation was observed. High rates of graft flow were measured mostly in patients with a long perfusion time, but in six instances there was no change in the flow due to reactive hyperaemia after a long perfusion.

RELATION BETWEEN TIME OF AORTIC OCCLUSION AND REACTIVE HYPERAEMIA An attempt was made to find a relation between the time of aortic crossclamping during anastomosis of the graft to the distal coronary artery and reactive hyperaemia.
The time of aortic occlusion was obtained by adding the period of cross-clamping, resulting in the total time without coronary perfusion. Between each period of aortic cross-clamping the myocardium was perfused for at least 3 minutes with blood at a temperature of $30^{\circ} \mathrm{C}$. The duration of aortic cross-clamping had no significant influence on the change of blood flow in the grafts during reactive hyperaemia.

RELATION OF GRAFT FLOW AND POSTOPERATIVE MYOCARDIAL INFARCTION Out of 40 patients, 11 developed myocardial infarction $(27.5 \%)$ according to the previously described criteria. Figure 3 shows the relation between control graft flow and myocardial infarction and its localization. There is no significant correlation between the graft flow and the appearance of myocardial infarction. A number of patients with high graft flow developed myocardial infarction and a number with very low graft flow did not. An attempt was also made to determine the relation between the artery bypassed and the localization of the infarcted area (Fig. 3). Generally a postero-inferior infarction appeared in patients with a bypassed right coronary artery or circumflex artery. The relation between the localization of anterior or lateral myocardial infarctions and the bypassed artery was less clear.

Of 27 patients in whom reactive hyperaemia was measured, eight developed postoperative myocardial infarction (Table III). The mean response of graft flow during reactive hyperaemia in patients with postoperative myocardial infarction was $13.0 \%$, and in a group of patients without myocardial infarction it was $26 \cdot 8 \%$.

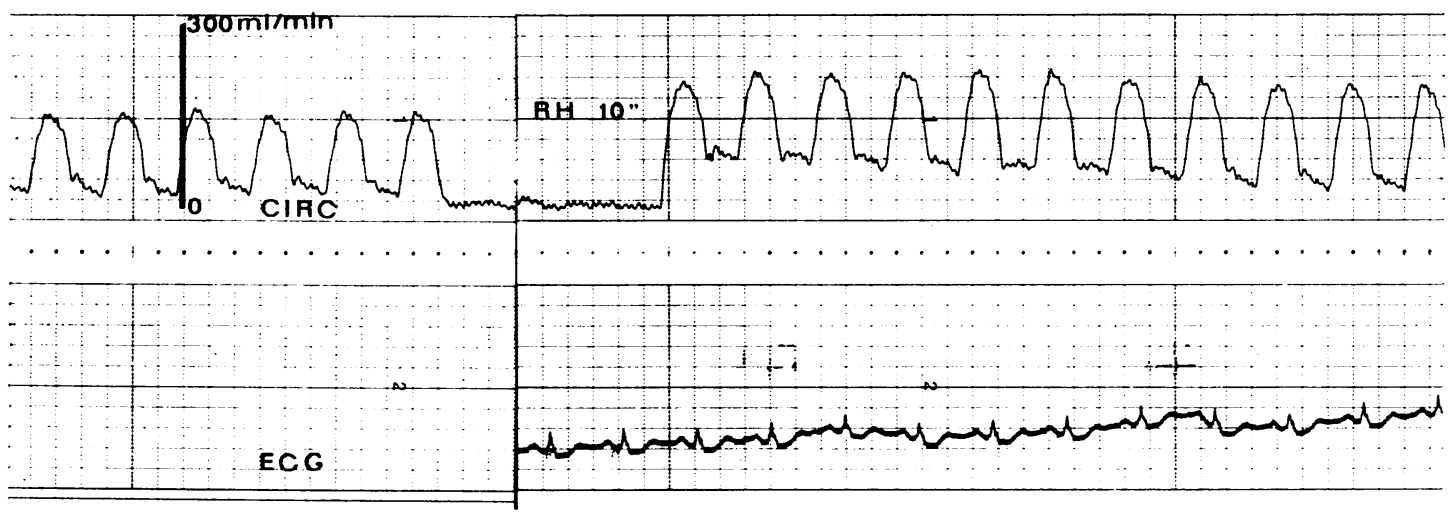

FIG. 2. Control flow and reactive hyperaemia $(R H)$ after 10 seconds' occlusion of the venous graft to the circumflex artery. 


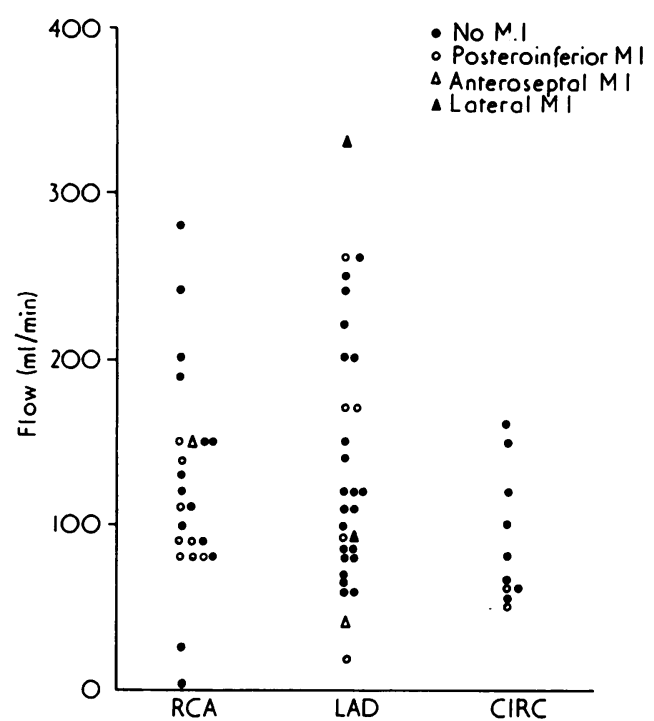

FIG. 3. Localization of myocardial infarction (MI) in relation to bypassed artery and control flow through the graft at the time of surgery.

\section{T A B L E I I I}

RELATION BETWEEN REACTIVE HYPERAEMIA (RH) AND POSTOPERATIVE MYOCARDIAL INFARCTION (MI)

\begin{tabular}{c|ccc}
\hline MI & No. of Patients & No. of Bypasses & $\begin{array}{c}\text { Increase at } \\
\text { Bypass Flow } \\
\text { (RH) }\end{array}$ \\
\hline+ & 8 & 13 & $13 \cdot 0 \%$ \\
\hline & 19 & 32 & $26.8 \%$ \\
\hline
\end{tabular}

This evident difference could indicate that patients with a relatively small effect of reactive hyperaemia on coronary bypass flow have a greater chance of developing myocardial infarction.

No relation could be established between myocardial reactive hyperaemia and the diameter of the coronary artery measured at the site of the anastomosis.

\section{DISCUSSION}

Aortocoronary bypass flow measurements are influenced by more variables than in other arteries (Edwards, 1971). The electromagnetic blood flow measurements are dependent on:

I technical factors:

1. the relation between the diameter of the electromagnetic probe and the diameter and thickness of the wall of the venous bypass

2. individual differences between electromagnetic probes
3. the disturbances caused by surgical tools and other sources of electromagnetic artefacts

4. the probe calibration, that obtained by saline perfusion in vitro differing slightly from that obtained in vivo.

II anatomical and physiological factors:

A. the arterial pressure and flow

B. the total resistance of the coronary circulation

1. the intravascular resistance:

a. the graft-to-artery diameter ratio (Furuse et al., 1972)

b. the degree of vascular resistance in the distal coronary artery (Edwards, 1971)

c. the degree of stenosis present in the proximal part of the coronary artery (Furuse et al., 1972)

d. the presence of collateral circulation from other coronary arteries (Bittar et al., 1972).

2. the extravascular resistance; this depends on the wall tension and compliance of the myocardium. The fibrillating heart and the heart with poor contractility have a lower extravascular resistance and an increase of the systolic fraction of the coronary flow (Olsson and Gregg, 1965a).

It is very difficult to predict the influence of all these factors on our results. They are affected to an unknown degree by the above-mentioned variables. Flow measurement after temporary occlusion of the aortocoronary grafts (induction of reactive hyperaemia) may give more information about peripheral coronary circulation than the measurement of graft flow alone (Khouri, Gregg, and Lowensohn, 1968; Bittar et al., 1972; van der Mark et al., 1972; Reneman and Spencer, 1972). Reactive hyperaemia is an autoregulative reaction and is caused by a decrease of total peripheral resistance in the affected part of the circulation due to vasodilatation as a response to metabolites produced by anoxia (Olsson and Gregg, 1965b) and a decrease of the extravascular resistance of the coronary bed (Coffman and Gregg, 1960).

Studies of myocardial reactive hyperaemia in healthy dogs (Olsson and Gregg, 1965a) show an increase of both systolic and diastolic flow to six to seven times the value of the control flow.

The increase of flow as a response to reactive hyperaemia observed during coronary artery surgery is much lower and did not appear in $24 \%$ of grafts (Bittar et al., 1972). In our studies on nine grafts of the 50 investigated $(18 \%)$, there was no influence on flow of temporary occlusion. 
It is supposed that several reasons are responsible for the absence of reactive hyperaemia. Bittar et al. (1972) mentioned the possibility that the unoccluded proximal part of the coronary artery and the damaged myocardium resulted in loss of the autoregulative mechanism. In $82 \%$ of the grafts reactive hyperaemia increased the flow from $17 \%$ to $26 \%$. In some of the patients an interesting reaction was observed. From flow measurements just after perfusion and a second time before closure of the sternum two different values were obtained. The control flow during the second measurement was sometimes lower but the response to reactive hyperaemia was higher. This could explain the high rates of the control flow in some instances and the lower reaction to reactive hyperaemia. It seems possible that the myocardium is in a state of reactive hyperaemia just after the end of extracorporeal circulation as a result of inadequate coronary perfusion (crossclamping aorta, air embolization) and druginduced peripheral vasodilatation. Return of the coronary perfusion to normal after a certain period of time may result in a decrease of coronary flow.

This supposition is not supported by our results concerning the relation between the degree of reactive hyperaemia and the time of aortic crossclamping and the time of extracorporeal perfusion. As reported by others, postoperative myocardial infarction as a result of coronary artery surgery occurs in 4 to $20 \%$ of patients (Bolooki et al., 1973; Brewer, Bilbro, and Bartel, 1973).

In our group of patients, $27.5 \%$ developed the electrocardiographic and enzymatic findings of myocardial infarction. There was no mortality in this group of patients and the postoperative course was uneventful in all. We did not succeed in establishing a relation between the flow through the bypass and the development of myocardial infarction. High flow did not prevent the appearance of myocardial infarction and can be related to insufficient myocardial perfusion during all periods of surgery-before (hypotension, arrhythmias), during (inadequate coronary perfusion or myocardial protection, surgical-technical difficulties), and in the early postoperative period (unstable circulation). It is not known to what extent infarction will impair the function of the myocardium and worsen the prognosis. The results of our study show a remarkable difference in response to reactive hyperaemia between patients with and without myocardial infarction. Patients with postoperative myocardial infarction had a lower hyperaemia response to temporary occlu- $\stackrel{\overrightarrow{\vec{S}}}{\vec{\theta}}$ sion of the graft $(13.0 \%)$ compared to a group without a perioperative myocardial infarction $(26.8 \%)$. This could indicate that the ability of the $\frac{\bar{\sigma}}{\overline{0}}$ peripheral coronary circulation to react with an $\stackrel{\mathbb{Q}}{\Omega}$ adequate hyperaemia may be an indicator of the \& result to be expected from revascularization.

We are indebted to Mr. W. H. Theunissen, Mr. F. W. $\overrightarrow{\vec{\omega}}$ Helebrant, and Mr. G. J. Bax for technical assistance.

\section{REFERENCES}

Bittar, N., Kroncke, G. M., Dacumos, G. C., Jr., ! Rowe, G. G., Young, W. P., Chopra, P. S., 근 Folts, J. D., and Kahn, D. R. (1972). Vein graft N flow and reactive hyperemia in the human heart. 음 Journal of Thoracic and Cardiovascular Surgery, 64,855 .

Bolooki, H., Sommer, L., Faraldo, A., Ghahramani, 을. A., Slavin, D., and Kaiser, G. A. (1973). The significance of serum enzyme studies in patients $\vec{v}$ undergoing direct coronary artery surgery. Journal of Thoracic and Cardiovascular Surgery, 65, 863.

Brewer, D. L., Bilbro, R. H., and Bartel, A. G. (1973). Myocardial infarction as a complication of $\bar{O}$ coronary bypass surgery. Circulation, 47, 58 .

Coffman, J. D. and Gregg, D. E. (1960). Reactive $\stackrel{\varnothing}{\mathbb{Q}}$ hyperemia characteristics of the myocardium. $\vec{F}$ American Journal of Physiology, 199(6), 1143.

Cooley, D. A., Dawson, J. T., Hallman, G. L., Sandiford, F. M., Wukasch, D. C., Garcia, E., and Hall, R. J. (1973). Aortocoronary saphenous vein bypass. Annals of Thoracic Surgery, 16, 380.

Edwards, W. S. (1971). Blood flow measurements 응 during coronary artery bypass operations. Annals of Thoracic Surgery, 12, 663.

Favoloro, R. G., Effler, D. B., Groves, L. K., Sheldon, W. C., and Sones, F. M. (1970). Direct myo- ̊̊ cardial revascularization by saphenous vein graft. $\frac{\mathrm{O}}{3}$ Annals of Thoracic Surgery, 10, 97.

Furuse, A., Klopp, E. H., Brawley, R. K., and Gott, 음 V. L. (1972). Hemodynamics of aorto-to- $\frac{D}{2}$ coronary artery bypass. Annals of Thoracic Surgery, 14, 282.

Grondin, G. M., Castonguay, Y. R., Lespérance, J., Љ Bourassa, M. G., Campeau, L., and Grondin, P. N (1972). Attrition rate of aorta-to-coronary artery saphenous vein grafts after one year. Annals of $\omega$ Thoracic Surgery, 14, 223.

—, Lespérance, J., Bourassa, M. G., Pasternac, A., Campeau, L., and Grondin, P. (1974). Serial angiographic evaluation in 60 consecutive patients $\stackrel{\oplus}{?}$ with aorto-coronary artery vein grafts 2 weeks, 1 year and 3 years after operation. Journal of $\overline{0}$ Thoracic and Cardiovascular Surgery, 67, 1.

, Meere, C., Castonguay, Y. R., Lepage, G., and $\frac{\mathscr{Q}}{\Phi}$ Grondin, P. (1971). Blood flow through aorta-to- $₫$ coronary artery bypass grafts and early postoperative patency. Annals of Thoracic Surgery, $12,574$. 
Johnson, W. D. and Lepley, D., Jr. (1970). An aggressive surgical approach to coronary disease. Journal of Thoracic and Cardiovascular Surgery, $59,128$.

Khouri, E. M., Gregg, D. E., and Lowensohn, H. S. (1968). Flow in the major branches of the left coronary artery during experimental coronary insufficiency in the unanesthetized dog. Circulation Research, 23, 99.

van der Mark, F., Frank, H. L. L., Buis, B., Brom, A. G., Bos, E., and Nauta, J. (1972). Significance of blood flow measurements in implanted aortocoronary bypass grafts (abstract). Circulation, 45-46, Supplement 2, 232.

Olsson, R. A. and Gregg, D. E. (1965a). Myocardial reactive hyperemia in the unanesthetized dog. American Journal of Physiology, 208, 224.

— and - (1965b). Metabolic responses during myocardial reactive hyperemia in the unanesthetized dog. American Journal of Physiology, 208 (2), 231.

Reneman, R. S. and Spencer, M. P. (1972). The use of diastolic reactive hyperemia to evaluate the coronary vascular system. Annals of Thoracic Surgery, 13, 477.

Requests for reprints to: Professor P. Kuijpers, University Hospital of St. Radboud, Nijmegen, The Netherlands. 